\title{
Plekhánov e a crítica estética marxista: entre a intenção e o gesto
}

\author{
Rodrigo Alves do Nascimento ${ }^{1}$
}

\begin{abstract}
If one wants to understand the history of Marxism in Russia, Georgi Plekhanov is an important and underrated thinker. Besides the introduction of classical texts by Marx in that country, Plekhanov was also responsible for the political guidelines that lead the organized workers' movement up until 1914 and the author of several innovative essays on Marxism and aesthetics. This paper will discuss this last aspect of Plekhanov's work, with emphasis to his essay "Art and Social Life", from 1912. I will discuss Plekhanov's formulations and the contradictions of a restrictive method, which did not prevent him from making important contributions to the understanding of the specificities of the aesthetic realm. In a dialogue with the bielinskian tradition, Plekhanov explored and started the debates of a Marxist aesthetic theory, an area of Marxism then unexplored.
\end{abstract}

Keywods: Georgi Plekhanov; aesthetic theory; art and social life.

Resumo: Georgi Plekhánov é parada obrigatória para quem se dedica a compreender a trajetória do marxismo na Rússia. Além de introduzir textos clássicos de Marx no país, foi responsável pelas diretrizes políticas que guiaram o movimento operário organizado até por volta de 1914 e por escrever textos de crítica estética inovadores nesse campo de pensamento. Este artigo se debruçará sobre esta última faceta de seu trabalho, mais depurada em seu ensaio Arte e Vida Social, de 1912, a fim de compreender como suas formulações, atravessadas que estavam pelas contradições de um método restritivo, não deixaram de trazer contribuições significativas para o entendimento do que denominava "especificidade do estético". Em um debate direto com a tradição bielinskiana, Plekhánov soube com ela dialogar e desbravar um campo de conhecimento até então praticamente inexplorado no marxismo.

Palavras-chave: Georgi Plekhánov; crítica estética; arte e vida social.

Como apresentar um pensador que, distante de nós no tempo e no espaço, converteu-se em referência "superada" de um materialismo determinista de início de século? Como fazer um balanço estético objetivo de uma forma de reflexão que tem como pressuposto a irreconciliável divisão de classes da sociedade e parte, portanto, da impossibilidade da análise distanciada? Ou ainda: como balizar a força desse pensamento sem recorrer a sua simples localização na história, ou até mesmo, à simples negação da história na compreensão de seus julgamentos?

Em que pese uma possível simplicidade no esqueleto geral do argumento teórico de Georgi Plekhánov, resgatá-lo sem a alcunha prévia do teleologismo, do sociologismo ou do determinismo é tarefa primeira de quem necessita se aproximar do problema de maneira correta. E, em um tempo no qual a restrição a seu pensamento é tão grande que ofusca até o reconhecimento de sua própria existência, optaremos por "limpar o terreno" e, a fim de nos aproximar de sua contribuição decisiva para o pensamento estético marxista, examinaremos os

\footnotetext{
${ }^{1}$ Mestre em Literatura e Cultura Russa pela FFLCH-USP. Realizou pesquisa com bolsa Fapesp em torno das encenações e da crítica da dramaturgia de Anton Tchékhov no Brasil. E-mail: rodrigotutao@yahoo.com.br.
} 
mecanismos internos de sua forma de pensamento na relação dinâmica com o efervescente momento histórico que acabou por definir seus limites e possibilidades.

O ensaio Arte e Vida Social, escrito por Plekhánov em 1912, por ocasião de algumas palestras sobre estética que realizava em Paris $^{2}$, apresenta argumentos que servem para a compreensão do lugar específico que seu pensamento ocupa na tradição crítica marxista e no contexto intelectual russo.

A forma da argumentação nesse ensaio tipifica um perfil que lhe é próprio ${ }^{3}$ : de início, não há movimento de abstração que alinhave o fenômeno estético como um todo. O pensador busca apresentar duas ou três situações que, pelo seu caráter representativo, servem de sustentação para uma tese que se desenha aos poucos. Ou seja, a preferência é por assegurar o sentido concreto, na comprovação mesma de sua historicidade, para logo após realizar qualquer conclusão de caráter geral. No entanto, como se vê, essa condição é aparente, tendo em vista que a seleção das próprias situações (ou exemplos) já vem filtrada pela suposição inicial do pensamento (e, ao final da leitura, é essa a tendência indutiva que predomina, a despeito do efeito intentado de predominância do concreto para a emergência de qualquer avaliação crítica).

Plekhánov, nessa precário movimento, pretende apresentar ao público as configurações sociais e as tendências históricas que subjazem à postura dos artistas e ao caráter de sua produção. Suas investidas nesse campo de estudos têm caráter pioneiro dentro do marxismo. Para Perry Anderson, intelectuais como Mehring e Plekhánov incumbiram-se da tarefa de, além de divulgar o marxismo em países ou regiões onde este era praticamente desconhecido, também estender a teoria marxista a campos do conhecimento não diretamente abordados por Marx e Engels (Anderson, p. 12-13). O trabalho específico de Plekhánov, portanto, não se prestou a um desenvolvimento complexo da teoria estética marxista, antes avançou em pontos específicos, deu sustentação e sistematização a esboços feitos de passagem por Marx e Engels em seus textos e cartas.

Isso se torna mais interessante ainda se levarmos em conta o fato de que o cenário russo, a despeito de toda a efervescência revolucionária e das contribuições de pensadores como Trótski e Lunatchárski, não ofereceu nenhum aporte de peso nesse campo. Somente a

\footnotetext{
${ }^{2}$ Nesse período, Plekhánov encontrava-se em exílio na Europa. Já era considerado então o renomado "pai do marxismo" na Rússia, tanto pela sua participação no grupo Emancipação do Trabalho (fruto de um rompimento teórico-prático com o populismo), como pelo já prolongado trabalho de tradução e divulgação dos clássicos marxistas em solo russo. Os escritos de Plekhánov tiveram tamanha influência no país que, pelo menos até 1914, foram as principais referências para a organização do movimento revolucionário de orientação marxista.

${ }^{3}$ Como podemos comprovar também em A Concepção Materialista da História (Rio de Janeiro: Paz e Terra, 1980).
} 
partir da década de 1930 é que emergirão no Ocidente ${ }^{4}$ as principais influências estéticas do marxismo, vindas de Lukács, Brecht, Bloch, Benjamin, Adorno, etc.

Em verdade, a ousadia de Arte e Vida Social está no fato de que, até então, nos meios de tradição marxista (em certo sentido, recentes), o debate estético fora colocado na marginalidade. As influências marcantes do determinismo darwinista e das tendências científicas em fins do século XIX acentuaram uma perspectiva mecanicista na análise da relação entre estrutura social e processos ideológicos, artísticos e culturais. Nesse contexto, a tendência à banalização do tema, assim como a mera instrumentalização de caráter sociologizante da especificidade estética, se tornou a tônica das discussões. Veremos que Plekhánov não rompe de todo com essas tendências de abordagem (e isso lhe define o tom), mas apresenta um esforço dialético de compreensão de seu lugar na emulsificação no todo social.

Nesse sentido, no intuito de oferecer um balanço da tradição crítica russa, assim como de proporcionar ao crescente operariado uma chave de leitura para a compreensão do fenômeno estético, Plekhánov escreve vários ensaios, como "A Estética de Tchernichévski" (1905), “As Opiniões Literárias de Bielínski"5 (1905), "Máximo Górki: 'Os Inimigos"”, (1907), "Duas Palavras aos Leitores Operários"” (1885), etc. Ao contrário do que caracterizará muitos artistas da geração revolucionária, Plekhánov não negou a contribuição decisiva da geração de pensadores oriundos da linhagem bielinskiana. Encontraria ali o gérmen de um pensamento que via no comprometimento ideológico do artista e do pensador um aspecto central do trabalho analítico. No entanto, realizou o movimento de distanciamento e, ao analisar as “opiniões literárias de Bielínski”, localizou a dificuldade do crítico em considerar a necessária especificidade do objeto artístico. Segundo ele, no momento em que, ao criticar os adeptos da arte pela arte e comentar o aspecto filosófico da poesia de Shakespeare, Bielínski estabelece uma relação de identidade entre conteúdo poético e conteúdo filosófico. Plekhánov parte do pressuposto inicial (daí seu movimento de argumentação indutivo, como constatado acima) de que "a arte expressa a vida", mas realiza a partir daí uma importante mediação: "Mas o problema é saber como esta arte concebia a expressão de suas ideias com o auxílio de imagens que decorrem da própria natureza da arte” (Plekhánov, 1955, p. 179).

\footnotetext{
${ }^{4}$ Não entraremos nesse veio de interpretação, tentando compreender os motivos inerentes a esse fôlego ocidental (sendo que o processo revolucionário se deu de maneira geral na Rússia), ainda que uma pista valiosa esteja nas interpretações de alguns líderes revolucionários a respeito da "cultura proletária" e da emergência, na década de 1930 do estalinismo e do realismo soviético.

5 Texto tradicionalmente selecionado pela crítica, que faz parte do estudo "Os Destinos da Crítica Russa", publicado em partes na revista Novoie Slovo (“A Nova Palavra”), de 1905.

${ }^{6}$ Este texto apareceu pela primeira vez na edição no 5 da revista Sovremienni Mir ("O Mundo Contemporâneo"), de 1907.

${ }^{7}$ Artigo datado de 25 de abril de 1885, escrito por Plekhánov em Genebra, como prefácio para a coleção de poemas “Os Cantos do Trabalho", editada pelo grupo Libertação do Trabalho.
} 
Num outro documento, "Duas Palavras aos Leitores Operários” (Plekhánov, 1955), talvez um dos mais antigos escritos de Plekhánov, o movimento de mediação é precário. Feitas as ressalvas de um documento dirigido a operários recém-alfabetizados, não podemos poupar a análise de suas sérias limitações. Até porque, é justamente o operariado (o interlocutor objetivado pela práxis marxista) que deveria ter acesso a uma compreensão mais refinada dos processos sociais e ideológicos (ainda que com as necessárias e difíceis mediações de linguagem). É de seu documento que retiramos:

De há muito sabe-se que cada povo tem a sua poesia: suas produções poéticas possuem um conteúdo tanto mais profundo quanto mais é instruído e desenvolvido esse povo. Do mesmo modo, pode-se dizer que cada classe social tem a sua poesia, na qual se põe o seu conteúdo particular. (...) Compreendeis, leitores, que tal poesia <a poesia da nobreza> não poderia entusiasmar senão os senhores nobres e quase não deviam ser apreciadas pelos camponeses, essas "pessoas" que se viam obrigadas a "fugir diante dos guerreiros que galopam". (Plekhánov, 1955, p. 204)

Essa análise de Plekhánov parte da premissa de que, no contexto da luta de classes, as diferentes classes sociais possuem formas próprias de representação artística da realidade. A princípio, o argumento não é de imediato refutável, na medida em que o próprio Bakhtin, anos mais tarde, veria na carnavalização o recurso encontrado pela massa popular (camponeses e operários) para satirizar a existência tipicamente mesquinha, esbanjadora e gananciosa dos poderosos, como forma de constituir uma identidade das culturas subalternas. No entanto, a análise de Plekhánov parece privilegiar a coexistência relativamente equilibrada de ambas, o que parece se distanciar da famosa assertiva de Marx: "As ideias dominantes de uma época são as ideias da classe dominante" (em todas as formas e nuances possíveis). Não há, como vemos, nenhum recurso à possibilidade de uma ideologia hegemônica (ainda que esse aspecto da ideologia seja, em Arte e Vida Social, um elemento central). Além disso, as formas estéticas da classe dominante seriam de todo execradas pelos explorados? Ainda em "Duas Palavras aos Leitores Operários”, o autor recorre ao mesmo argumento para dizer, a respeito de Eugênio Oniéguin, de Púchkin, que "um operário simplesmente não compreenderá o conteúdo desse romance", tendo em vista a vida leve e entediante do personagem - típico “pertencente das classes superiores” (Plekhánov, 1955, p. 204-205). A realidade de seus contemporâneos - e, principalmente, da União Soviética - parece ter demonstrado o contrário.

Leandro Konder, ao analisar uma outra passagem de Plekhánov ${ }^{8}$, veria nessa atitude uma "tendência para reduzir a arte à sua gênese social" (Konder, p. 43), como argumento

\footnotetext{
${ }^{8}$ A respeito dessa tendência de simplificação do argumento, Konder localizou a própria pressuposição de dados falsos nas críticas de Plekhánov: "Umberto Bárbaro lembra que Plekhánov considerou o minueto como 'a
} 
único. Descaminhos como esse tenderam, a despeito de todas as ressalvas críticas de Plekhánov ao sociologismo (e às induções argumentativas), a inseri-lo numa cadeia de rechaços teóricos (também expandidos ao marxismo como um todo) que segue até hoje.

Mas atenhamo-nos à proposta crítica de Plekhánov apresentada em Arte e Vida Social, seu tratado mais longo e representativo sobre a arte. Dividido em três partes ${ }^{9}$, podemos dizer que, num primeiro momento, Plekhánov apresenta o problema da relação entre arte e vida social, e como ele vem sendo abordado pela crítica russa e europeia. Num segundo momento, trata do que podemos chamar de "caráter ideológico das obras de arte". E, na última parte, o autor tenta demonstrar o "caráter decadente da atual arte burguesa". A operação metodológica de Plekhánov já foi citada, logo na primeira página deste texto, como uma forma analítica (oriunda das próprias tendências de pensamento de sua época) que, mesmo a despeito de todas as ressalvas do autor sobre os riscos do mecanicismo e do reducionismo sociológico, acabam grassando o argumento.

Na primeira parte, Plekhánov se baseia na noção de desenvolvimento social para associar a ele diferentes níveis de produção artística. Derivamos daí a ideia de que, quanto mais desenvolvida economicamente a sociedade, mais desenvolvida a sua produção artística e o pensamento crítico que a tem como objeto. E é justamente a crítica que "atinge um certo grau de desenvolvimento" que colocará para si o problema da "relação entre a arte e a vida social" (Plekhánov, 1969, p. 11). O pensador vê aí duas tendências básicas que se antagonizam na abordagem do problema: a visão utilitarista da $\operatorname{arte}^{10}$, como instrumento para o desenvolvimento da consciência e como meio para a veiculação de ideias, e a visão da arte como um "fim em si" "11, puro prazer e fruição dos sentidos.

Limpando o terreno, Plekhánov esclarece que o problema está mal formulado. Não se deve trabalhar com o "dever ser" da arte, mas "do ponto de vista do que foi e do que é" (idem, p. 15). Há aqui dois movimentos: o de tentar se livrar do risco de chegar a (e partir de) conceitos abstratos de arte, e o de afirmar sua intrínseca historicidade. É nesse momento que o pensador busca localizar as condições sociais que favorecem a emergência do "utilitarismo"

expressão harmônica da psicologia de uma classe improdutiva e corrupta'; e observa que, no caso, Plekhánov cometeu um duplo equívoco: 1) ignorou que a origem do minueto era bem anterior àquela que ele lhe atribuía; 2) ignorou que o minueto foi, em sua origem, como tantas outras danças de salão, uma dança camponesa" (Konder, p. 43).

${ }^{9}$ Tomo como referência para debate a edição de 1969, da Civilização Brasileira, com tradução do espanhol de Eduardo Sucupira Filho.

$10 \mathrm{Na}$ tradição crítica russa, Plekhánov veria na geração de 60 (os populistas russos da linhagem de Tchernichevski e Dobroliúbov) os representantes dessa tendência.

${ }^{11}$ Aqui, o pensador resgata o Púchkin da época de Nicolau I:

"Não nascemos para a agitação da vida

Nem para o combate ou a ambição

Nascemos para a inspiração,

Para as orações e as doces melodias" (idem, p. 14). 
(o impulso artístico preso à "agitação da vida e do combate") e a perspectiva da isenção, da “arte pela arte" (idem, p. 14-15). Dois exemplos serão paradigmáticos:

1) Baudelaire e a crítica de Teófilo Gautier seriam representantes da mentalidade romântica que, saturada de projeções desesperadas, realiza uma crítica da mentalidade burguesa, mas, objetivamente, não pretende romper com o modo de vida burguês. Para isso, expressam um movimento de intensa valorização da sensibilidade, como refúgio à abjeção e ao utilitarismo das relações de capital. Seria a tendência da "arte pela arte" - nas palavras de Gautier: "não sujou a poesia e despertou no leitor a sensação do belo" (idem, p. 19). Para Plekhánov, a matriz de tal atitude estaria no fato de que "a tendência da arte pela arte surge quando existe um divórcio entre o artista e o meio social que o rodeia" (idem, p. 18). O divórcio, nesse caso, resgatado na sua historicidade, estaria no fato de que o Baudelaire desse período vivenciava o processo de reação da burguesia francesa, que agora se divorciava de seus antigos aliados para consolidar-se no poder. A atitude de protesto de românticos e parnasianos se constituiria enquanto um programa moral: os "decadentes" usavam cabelos longos, vestiam jalecos e exibiam uma forte palidez no rosto. Era preciso diferenciar-se dos lugares-comuns burgueses. Sua manifestação na arte seria, na visão de um parnasiano, "a vida ideal de quem já não tem vida real” (idem, p. 25).

2) O Baudelaire das revoltas de $1848^{12}$, o Púchkin do período de Alexandre $\mathrm{I}^{13}$ e os intelectuais do populismo russo seriam emblemáticos da perspectiva utilitarista. Plekhánov a concebe enquanto propensão do artista e da crítica aos problemas políticos de seu tempo, independentemente do lugar ocupado na "trincheira da luta de classes". Nesses exemplos em específico, tanto Baudelaire como Púchkin, nem sempre artistas defensores do projeto de "arte pela arte", estavam dispostos ao combate e à tomada de posição. Para Plekhánov, essa tendência tem sua gênese histórica nos momentos em que há considerável simpatia social a esse tipo de formulação. Para Baudelaire, a consonância com um momento histórico em que a aliança entre amplos setores da sociedade permitia bandeiras de caráter universalista. Para Púchkin, o pensamento num período ainda não marcado pela repressão e pelo "fechamento" do império de Nicolau I. Para o populismo russo, o clima de efervescência e indignação que, ao menos nos meios estudantis e em setores de razoável ilustração, permitia levantar bandeiras

\footnotetext{
${ }^{12}$ Segundo Plekhánov, nesse período Baudelaire editava a revista Le Salut Public, na qual "qualificava de pueril a teoria da arte pela arte e proclamava que a arte deveria perseguir fins sociais" (idem, p. 24).

${ }^{13}$ O Púchkin desse período seria, segundo Plekhánov, o militante das causas do "povo", que não devia se contentar com "chibata, ergástulos e cadafalsos":

"Ah! Para qualquer lado que volta o olhar,

Látegos por toda a parte, por toda a parte cadeias,

A ignomíniade leis nefandas

Lágrimas impotentes de escravidão;

Por toda parte poder arbitrário

Na tenebrosa noite dos preconceitos, etc." (idem, p. 15)
} 
de cunho progressista e revolucionário ${ }^{14}$. Percebemos aqui que, analisando objetivamente o movimento da história, esse tipo de instrumentalização da arte tem caráter "legítimo", já que possui respaldo social. No entanto, como diferenciar a "instrumentalização revolucionária" (de caráter "positivo" para o desenvolvimento histórico ${ }^{15}$ ) da "instrumentalização reacionária"? Para resolver esse impasse, Plekhánov se debruça sobre a compreensão do caráter ideológico das obras de arte, explicitado na segunda parte de seu trabalho.

Lançadas as bases materiais para a compreensão do fenômeno artístico, Plekhánov apresenta a necessidade de localização de seu sentido ideológico, como forma de situá-lo mais acertadamente no mecanismo estrutura-superestrutura e entender sua efetividade no processo histórico. Dada a limitação do método, pouco propenso a uma radicalização dialética, Plekhánov reduz o sentido da obra de arte ao esquema: "o mérito da obra está em seu conteúdo, no que ela diz" (idem, p. 31), embaralhando a compreensão do leitor, que depara, logo após, com a assertiva: "um artista é um artista e um publicista um publicista, mas isso não quer dizer que a obra não tenha conteúdo ideológico" (idem, p. 32). A confusão está justamente no fato de que não se esclarece qual é a especificidade do trabalho artístico, que lhe garante um estatuto próprio que o diferencie do trabalho de um publicista. Ora, para o marxismo ocidental, que desenvolverá com mais acuidade essa ideia, a dialética formaconteúdo é fundamental para a compreensão da especificidade do estético. Anos mais tarde, Lukács dirá: “a alma é a forma” (Lukács, 1985, p. 122).

No entanto, a redução parece suficiente para Plekhánov, e em função do conteúdo será avaliado se o escritor "acertou a mão" na história: "a corrente certa atrai escritores de maior talento", porque "as obras verdadeiramente artísticas sempre exprimem algo" (op. cit., 1969, p. 31). O risco da fórmula é previsível: parte-se de um clássico já consolidado na história para depois justificar seu "acerto histórico" ou, em função de seu conteúdo inerentemente progressivo, a obra se consolida enquanto tal?

Mas Plekhánov fará a ressalva de que a obra verdadeiramente artística se consolida porque nem todo conteúdo pode ser expresso na obra de arte. O dinheiro perdido de um banqueiro, a mesquinha tristeza de um agiota que levou um grande calote numa negociata não teriam função estruturante numa verdadeira obra de arte. Para o pensador, "quanto mais

\footnotetext{
${ }^{14}$ Há nessa tendência uma especificação importante feita por Plekhánov. Para ele, a "arte utilitária" poderia servir tanto ao espírito revolucionário quanto ao espírito conservador: "De tudo isso se depreende claramente que a concepção utilitarista da arte se compagina tão bem com o espírito conservador quanto com o espírito revolucionário" (idem, p. 30). Instrumentalizações reacionárias ficaram evidentes na história, segundo Plekhánov, nas produções de Lamartine, Du Camp, Dumas, assim como nas diretrizes e opiniões estéticas de governantes como Luís XIV e Napoleão Bonaparte.

${ }^{15}$ Tento aqui utilizar uma terminologia típica do modo de pensar plekhanoviano, a saber: o do caráter positivo do desenvolvimento da história, no sentido da herança positivista, calcada na ideia de "evolução". A revolução teria, aqui, caráter progressivo (independentemente de seu protagonista), pois significaria uma reconfiguração estrutural da sociedade, em ambiente de acirrada luta de classes, que proporcionaria o movimento do "motor da história".
} 
elevada e universal" a obra, mais ela comunica (idem, p. 32). E aqui Plekhánov dialoga com uma tradição mais antiga, da qual o próprio Tolstói seria tributário, de que um dos objetivos fundamentais da obra de arte é "comunicar"16.

Na esteira de uma necessária análise ideológica da obra, Plekhánov parte para a desconstrução de uma ideia absoluta de arte. Para isso, dialoga com a afirmação de Turguêniev de que “a Vênus de Milo é mais indiscutível que os princípios de 1789” (idem, p. 33). Contestando esse axioma, mobilizará a ideia de que a Vênus de Milo se tornava cada vez mais “indiscutivelmente bela” à medida que se consolidavam os princípios de 1789 na França (ascensão burguesa e declínio do padrão religioso de beleza, com a valorização do profano).

De início, o argumento parece produtivo, mas logo cai no esquema determinista:

O ideal de beleza que impera em momento dado em determinada sociedade ou em determinada classe da sociedade depende em parte das condições biológicas do desenvolvimento do gênero humano, que são as que determinam, entre outras coisas, as peculiaridades raciais; e em parte das condições históricas em que surgiu e existe essa sociedade ou classe. E por isso, precisamente, o dito ideal é sempre muito rico de conteúdo inteiramente condicionado e nada absoluto. (idem, p. 35)

Na terceira e última parte de seu ensaio, Plekhánov "esgarça" sua crítica e procede à realização de um esboço de programa. Tenta demonstrar a decadência da atual arte burguesa (então sua contemporânea) sob o argumento de que as vertentes simbolistas e vanguardistas, numa exaltação incomum da forma e do "eu absoluto", se afastariam das tendências mais progressistas de seu tempo. Segundo ele, ficaria cada vez mais difícil ser um adepto da "arte pela arte" no pós-1848, e, após o ascenso das tendências românticas, os artistas teriam compreendido que é impossível a existência de uma forma sem conteúdo, assumindo, assim, um determinado conteúdo (a exaltação do eu). Essa maneira de pensar teria ligações estreitas com um "neorromantismo nietzschiano", adepto da teoria da "potência individual" diante da realidade. Isso culmina no arremate: "quando um artista se inspira em uma ideia falsa, deita a perder a própria obra" (idem, p. 55). Desse modo, os “decadentistas" russos estariam marcados com a cruz da irracionalidade, pela redundância de temas e formas que só visariam ao embelezamento do eu, pela indiferença ao conteúdo ideológico e pela simpatia pelo "nada".

$\mathrm{Na}$ pintura, onde a dimensão formal parece ser um aspecto mais saliente, Plekhánov também será praticamente impermeável às inovações apresentadas pelas vanguardas. Segundo ele, o cubismo representaria um "demencial método de criação", e exagera no argumento de que, nessa perspectiva, "qualquer forma estranha pode ser considerada o que ela não é" (idem, p. 69). Segundo ele, a teoria da arte pela arte teria chegado aqui ao seu mais completo

\footnotetext{
${ }^{16}$ A respeito desse aspecto no pensamento estético tolstoiano, ver O que é Arte?.
} 
absurdo. A pintura impressionista também seria expressão da decadência da sensibilidade burguesa por se restringir à periferia dos fenômenos, tendo como parâmetro a agudização dos sentidos (“Mais Luz!") em detrimento de um aperfeiçoamento da ideia (idem, p. 67).

O parâmetro de Plekhánov se apresenta agora de maneira mais clara. O realismo seria o paradigma criativo que teria maiores condições de comunicação com o real, por juntar forma e conteúdo corretos, numa expressão que espelhasse o movimento da sociedade (algo ideologicamente acertado). Essa limitação reflexiva - certa teleologia em torno do paradigma realista (modelar), somada a uma limitação dialética (relação base-superestrutura) - contribuiu para a esquematização do pensamento de Plekhánov. E essa debilidade teria sido localizada por Gramsci, que teria dito que, "ao defender o princípio materialista da dependência da arte em relação à vida social, Plekhánov dá-lhe uma formulação estreita, de dependência servil da criação estética ante a ditadura implacável e mesquinha das condições socioeconômicas" (Konder, p. 41).

Suas explanações iniciais de Arte e Vida Social renderam prolongadas polêmicas com Lunatchárski - pensador mais propenso à compreensão das inovações formais e à contribuição das vanguardas artísticas (em especial na pintura) -, além de terem sido mobilizadas, de maneira oportunista, para a justificação do posterior realismo soviético.

O salto das projeções de futuro (com características de um programa de longo prazo) esboçam a arte na sociedade comunista, em que a organização social justa ofereceria o terreno propício para a emergência de uma forma de expressão que não mais opusesse estética e ética. Desaparecendo as classes, desapareceria o utilitarismo estreito (op. cit., 1969, p. 72).

Observadas as contradições, não poderíamos dizer que os descaminhos de Plekhánov escurecem a relevância de sua obra na trajetória do pensamento marxista. Ela não só trouxe à tona um debate geralmente ignorado pela tradição, como também tentou (num processo altamente contraditório, como vimos) dar ao estético o seu estatuto específico - ainda que essa intenção, limitada que fora pelo pressuposto e pelo método, não tenha se convertido em gesto concreto.

No entanto, "de uma perspectiva dialética, um descaminho publicado é melhor que nada" ${ }^{\prime 17}$.

\section{Referências bibliográficas}

Anderson, Perry. Consideraciones sobre el Marxismo Occidental. México: Siglo XXI Editores, 1991.

\footnotetext{
${ }^{17}$ Comentário de Roberto Schwarz a respeito de uma reavaliação crítica se seu ensaio "Didatismo e Literatura", publicado pela primeira vez na década de 70 (Schwarz, 2008, p. 56).
} 
Bottomore, Tom (org.). Dicionário do Pensamento Marxista. Rio de Janeiro: Zahar, 2001. Konder, Leandro. Os Marxistas e a Arte. Rio de Janeiro: Civilização Brasileira, 1967.

Lukács, Georgy. El Alma y las Formas/Teoría de la Novela. México: Grijalbo, 1985. . Ensaios sobre Literatura. Rio de Janeiro: Civilização Brasileira, 1968.

Plekhánov, George. Arte e Vida Social e Cartas sem Endereço. São Paulo: Brasiliense, 1969. Tradução de Eduardo Sucupira Filho.

Arte e Vida Social. Rio de Janeiro: Editora Lux, 1955. Tradução de Ary de Andrade. A Concepção Materialista da História. Rio de Janeiro: Paz e Terra, 1980.

Schwarz, Roberto. O Pai de Família e Outros Ensaios. São Paulo: Companhia das Letras, 2008 .

Tolstói, Leon. O que é Arte? São Paulo: Experimento, 1994.

Trotski, Leon. Literatura e Revolução. Rio de Janeiro: Zahar, 2007. 